\title{
Variant surface antigens in cerebral malaria: distinct from others and similar to each other?
}

\author{
Agnès Aubouy ${ }^{1 *}$, Nabila Kheliouen ${ }^{1,2}$, Nicaise Tuikue-Ndam ${ }^{1,2}$, Firmine Viwami ${ }^{1}$, Francis Lalya ${ }^{3}$, \\ Else C Eboumbou Moukoko ${ }^{4,5}$, Christophe Rogier ${ }^{4}$, Philippe Deloron ${ }^{1,2}$ \\ From Parasite to Prevention: Advances in the understanding of malaria \\ Edinburgh, UK. 20-22 October 2010
}

Immunological protection against Plasmodium falciparum blood stages is mainly antibody mediated $[1,2]$. Variant surface antigens (VSA) expressed on the surface of P. falciparum-infected red blood cells constitute a key for parasite sequestration and immune evasion [3]. In distinct malaria clinical presentations, as placental malaria, specific antibody response against VSA provides protection [4].

In the current study, we investigated in distinct clinical groups of malaria patients, the antibody response specifically directed against VSA expressed by parasites isolated from a given clinical presentation, and particularly isolates obtained from cerebral malaria (CM) patients. Plasma and isolates were obtained from four groups of Beninese subjects: healthy adults ( $\mathrm{HA}, \mathrm{n}=34)$, patients presenting uncomplicated malaria $(\mathrm{UM}, \mathrm{n}=62)$, cerebral malaria $(C M, n=41)$, or pregnancy-associated malaria (PAM, $\mathrm{n}=24$ ). Isolates were tested for their clonality by $m s p 1$ and $m s p 2$ genotyping. The reactivity of plasma samples from each clinical group was measured by flow cytometry against parasites isolated from individuals from each clinical group.

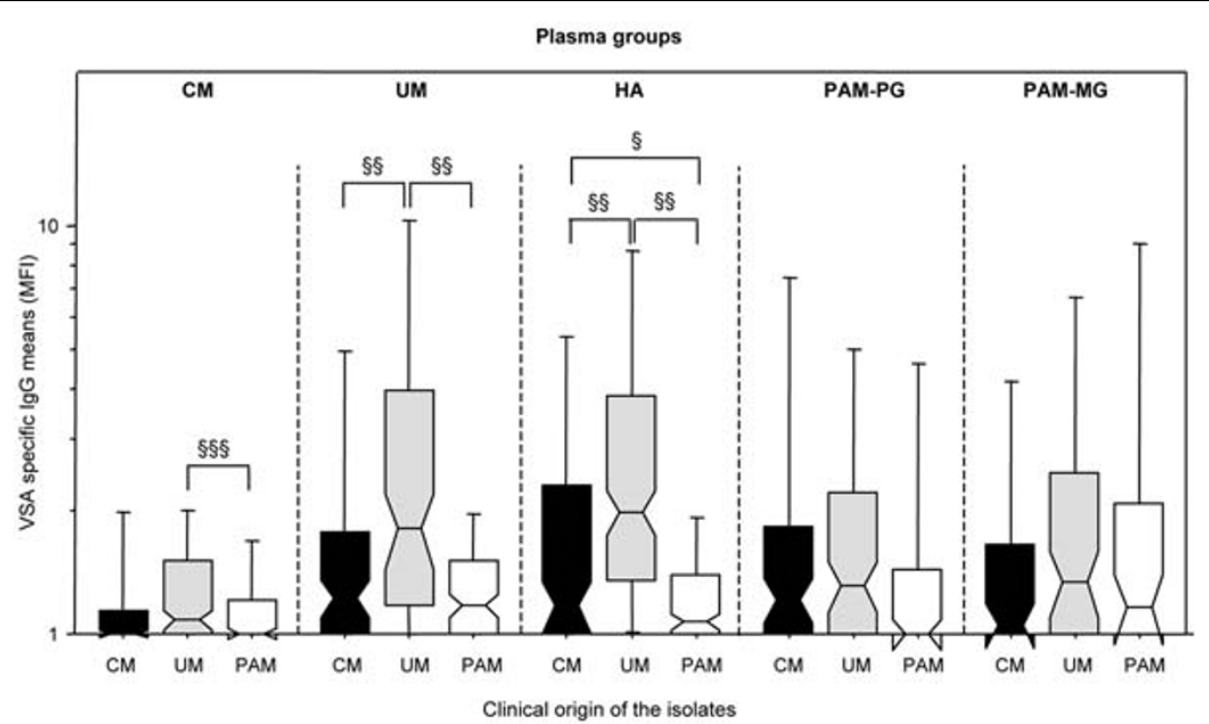

Figure 1 Relative levels of VSA specific lgG to heterologous P.falciparum isolates according to the clinical origin of the $P$. falciparum isolates, and to the plasma group. PG: primigravidae, MG: multigravidae. Errors bars indicate standard errors. Groups were compared all together by ANCOVA (*** $\mathrm{P}<.0005$, * $\mathrm{P}<.05$, ns. non significant), and two factor ANOVA ( $\left.{ }^{\S \S} \mathrm{P}<.0005,{ }^{\S \S} \mathrm{P}<.005,{ }^{\S} \mathrm{P}<.05\right)$.

${ }^{1}$ Institut de Recherche pour le Développement(IRD) UMR216, Paris, 75006

France

Full list of author information is available at the end of the article

(c) 2010 Aubouy et al; licensee BioMed Central Ltd. This is an open access article distributed under the terms of the Creative Commons Attribution License (http://creativecommons.org/licenses/by/2.0), which permits unrestricted use, distribution, and reproduction in any medium, provided the original work is properly cited. 

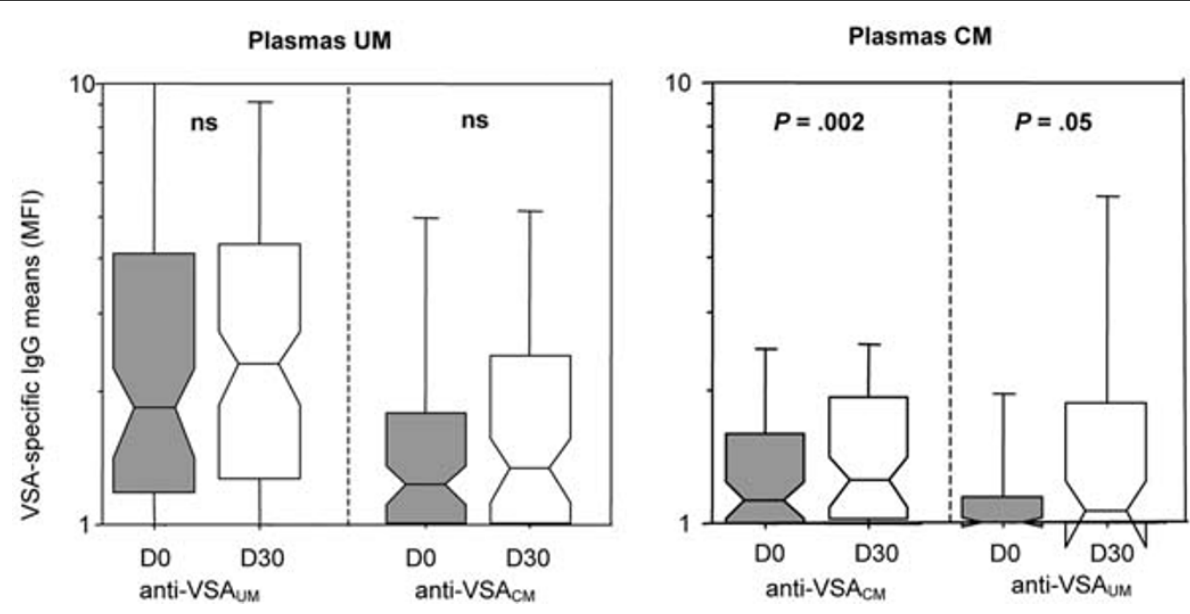

Figure 2 Acquisition of VSA-specific IgG during the month following $P$. falciparum infection in plasmas samples from UM $(n=121)$ and CM $(n=$ 56) patients. UM (A, B) or $C M(C, D)$ plasma samples were tested against $P$. falciparum isolates from UM patients $(A, D)$ or from $C M$ patients $(B, C)$. Centerlines indicate medians, boxes indicate the 25 th and 75 th percentiles of data points, bars indicate the 10th and 90th percentiles and circles are outliers. Differences are derived from the Wilcoxon rank test for paired comparisons, ns: non significant.

The levels of clonality were similar in isolates from all clinical origins. In healthy adults and children presenting $\mathrm{UM}, \mathrm{VSA}_{\mathrm{UM}}$ antibody levels were higher than $\mathrm{VSA}_{\mathrm{CM}}$ antibody levels (Figure 1). In both PAM plasma groups (primigravidae and multigravidae), antibody levels against the three types of isolates were similar. One month after infection the level of anti-VSA antibodies able to recognize heterologous $\mathrm{VSA}_{\mathrm{CM}}$ variants was increased in CM patients. In UM patients, antibody levels directed against heterologous $\mathrm{VSA}_{\mathrm{UM}}$ were similar during the infection and one month later (Figure 2).

The existence of shared $\mathrm{VSA}_{\mathrm{CM}}$ epitopes was shown but does not necessarily involve prevalent epitopes. Prevalence is more probably due to a fine balance between transmission intensity, antibody repertoire and environmental factors.

\section{Author details}

'Institut de Recherche pour le Développement(IRD) UMR216, Paris, 75006 France. ${ }^{2}$ Université Paris Descartes, Faculté de Pharmacie, Paris, 75270, France. ${ }^{3}$ Paediatric Department, Centre National Hospitalo-Universitaire (CNHU), Cotonou, Benin. ${ }^{4}$ Unité de recherche en biologie et épidémiologie parasitaires, Institut de Recherche Biomédicale des Armées, UMR6236, Marseille, France. ${ }^{5}$ Département des Sciences Biologiques, Faculté de Médecine et des Sciences Pharmaceutiques, Université de Douala, BP2701, Douala, Cameroun.

Published: 20 October 2010

\section{References}

1. Cohen S, McGregor IA, Carrington S: Gamma-globulin and acquired immunity to human malaria. Nature 1961, 192:733-7.

2. Bouharoun-Tayoun H, Attanath P, Sabchareon A, Chongsuphajaisiddhi T, Druilhe P: Antibodies that protect humans against Plasmodium falciparum blood stages do not on their own inhibit parasite growth and invasion in vitro, but act in cooperation with monocytes. J Exp Med 1990, 172:1633-41.
3. Bull PC, Lowe BS, Kortok M, Molyneux CS, Newbold Cl, Marsh K: Parasite antigens on the infected red cell are targets for naturally acquired immunity to malaria. Nat Med 1998, 4:358-60.

4. Brabin BJ: An analysis of malaria in pregnancy in Africa. Bull World Health Organ 1983, 61:1005-16.

doi:10.1186/1475-2875-9-S2-02

Cite this article as: Aubouy et al: Variant surface antigens in cerebral malaria: distinct from others and similar to each other? Malaria Journal 2010 9(Suppl 2):O2.

\section{Submit your next manuscript to BioMed Central and take full advantage of:}

- Convenient online submission

- Thorough peer review

- No space constraints or color figure charges

- Immediate publication on acceptance

- Inclusion in PubMed, CAS, Scopus and Google Scholar

- Research which is freely available for redistribution 